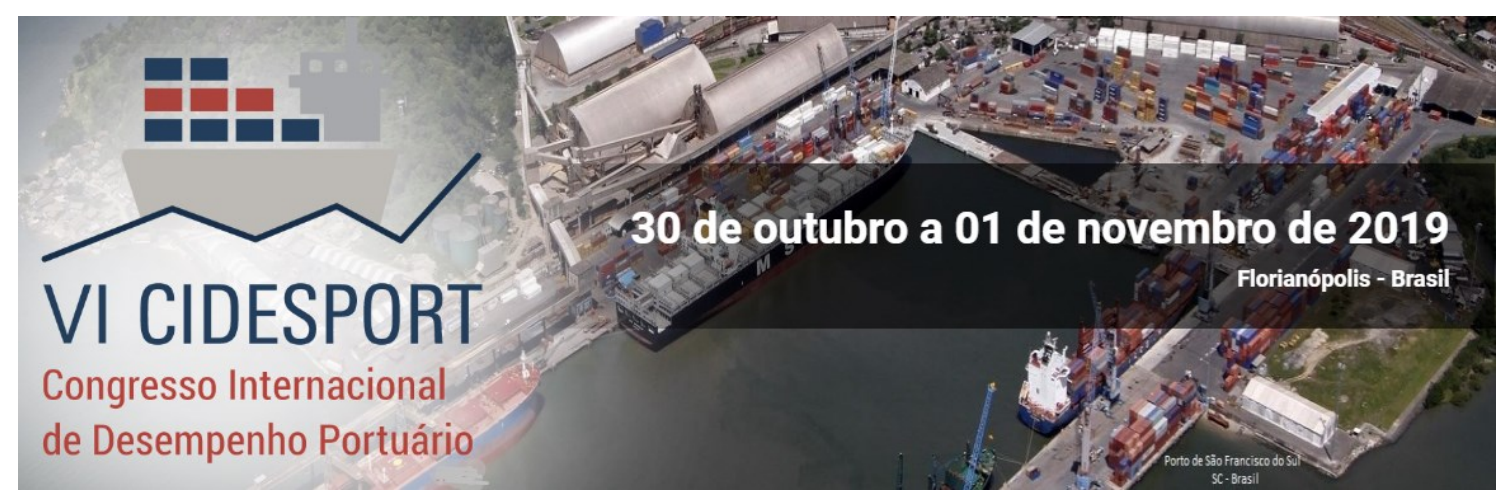

\title{
EDUCAÇÃO COMO MUDANÇA SOCIAL - RESULTADOS DO ACOMPANHAMENTO ESCOLAR NA ÁREA DE INFLUÊNCIA DO PORTO PECÉM - CIPP S.A
}

\author{
Maria do Livramento de Barros Oliveira \\ MRS Ambiental, Porto de Pecém
}

Maria Quilana Viégas Ferreira MRS Ambiental, Porto de Pecém

\section{Márcia Emanuelle Teixeira Maia Mattos} MRS Ambiental, Porto de Pecém

\section{leda Passos Theophilo Gaspar de Oliveira MRS Ambiental, Porto de Pecém}

\author{
Sylvio de Campos Goncalves Neto
} MRS Ambiental, Porto de Pecém

Resumo: O Porto do Pecém é administrado pela Companhia de Desenvolvimento do Complexo Industrial e Portuário do Pecém S.A (CIPP S.A) está localizado a $60 \mathrm{~km}$ de Fortaleza nos Municípios de São Gonçalo do Amarante e de Caucaia, no Ceará. Esse porto foi construído para integrar o Complexo Industrial e Portuário do Pecém - CIPP que se encontra em constante expansão. Além do transporte multimodal de cargas o Porto objetiva tornar os cidadãos agente transformadores da realidade local. Por meio do Programa de Educação Ambiental do Porto do Pecém são desenvolvidas atividades transformadoras de cunho socioambiental, no caso do presente relato, é apresentada a educação como mudança social por meio do desenvolvimento de reforço escolar no contra turno do período escolar. Assim, o objetivo do projeto é melhorar o desempenho dos alunos de escolas municipais na área de influência do Porto do Pecém, proporcionar o ingresso deles em escolas profissionalizantes do ensino médio e valorizar a comunidade por meio da contratação de monitores locais incentivando a formação de profissionais qualificados. Os monitores passaram por uma formação com metodologia pedagógica lúdica de integração de conceitos sociais e ambientais e aplicaram os conhecimentos em aulas do $6^{\circ}$ ao $9^{\circ}$ ano de português e matemática em três escolas da área de influência do Porto do Pecém. Dessa forma, obtivemos como resultados melhorias no desempenho escolar na maioria das séries e escolas trabalhadas, aprovação dos alunos que participaram do reforço escolar de cerca de $80 \%$ nas escolas profissionalizantes da região, formação de monitores da própria comunidade como agentes de inspiração e transformação social.

Palavras chave: Porto, educação, reforço escolar, educação ambiental, gestão ambiental.

*A revisão gramatical, ortográfica, ABNT ou APA foi realizada pelos autores. 


\section{INTRODUÇÃO}

O Porto do Pecém é administrado pela Companhia de Desenvolvimento do Complexo Industrial e Portuário do Pecém S.A (CIPP S.A) está localizado a $60 \mathrm{~km}$ de Fortaleza nos Municípios de São Gonçalo do Amarante e de Caucaia, no Ceará. Esse porto foi construído para integrar o Complexo Industrial e Portuário do Pecém - CIPP que se encontra em constante expansão.

O Porto do Pecém tem como missão oferecer soluções seguras e eficientes de logística de transporte multimodal de cargas, atuando como indutor de novos negócios, diretamente ou por meio de parcerias, promovendo o desenvolvimento sustentável para o Estado do Ceará. Além disso um dos valores organizacionais do Porto do Pecém é o compromisso socioambiental, que visa a adoção de práticas solidárias, com uso sustentável dos recursos em prol das gerações atuais e futuras. Dessa forma este terminal portuário possui várias atividades em prol do seu compromisso socioambiental.

O Porto do Pecém tem programas e projetos nos distritos Pecém e Taíba, onde estão localizadas a Colônia de Pescadores e Aquicultores Profissionais de São Gonçalo do Amarante (Z-06) e o Distrito de Cumbuco onde está a sede da Colônia de Pescadores e Aquicultores Profissionais de Caucaia (Z-07).

A implantação de indústrias no estado do Ceará vem crescendo de forma exponencial, mesmo com a crise. Segundo a última Pesquisa Industrial Anual realizada pelo Instituto Brasileiro de Geografia e Estatística (IBGE) lançada em 2017 o estado teve um aumento no potencial industrial entre os anos de 2008 e 2017 de 3,4 pontos percentuais, sendo o segundo estado que mais cresceu, ficando atrás apenas do Pernambuco, que aumentou $8,5 \%$ (IBGE, 2017).

Para capacitar a população a esses novos empregos o estado do Ceará, desde 2008 começou a investir mais na educação profissionalizante, criando assim as primeiras Escolas Estaduais de Educação Profissional. Estas escolas possibilitam que o aluno saia do ensino médio com formação técnica em diversas áreas, além de um contato com o mercado de trabalho ainda em sua formação básica uma vez que quando cursam o $3^{\circ}$ ano do ensino médio os alunos fazem estágios em empresas (CEARÁ, 2018).

Sabe-se que a educação é o principal meio de modificar a realidade de uma comunidade, cidade, estado e país. Por isso, a Companhia de Desenvolvimento do Complexo Industrial e Portuário do Pecém CIPP S.A dentro do seu Programas de Educação Ambiental (PEA) passou a investir na área de educação com acompanhamento escolar, este projeto é chamado de reforço escolar. É possível verificar que além de estar presente no PEA a transformação social através da educação também faz parte dos valores do complexo visto que é contemplada em dois pontos, sendo eles: compromisso socioambiental com a utilização de práticas solidárias e Progressão e melhoria continuada, que busca em um esforço contínuo a melhoria da qualidade em termos humanos (CEARÁ).

O presente projeto é desenvolvido na Linha de Ação de Projeto de EduComunica-Ação Ambiental e Valorização da Cultura e das Artes da Pesca, pois as atividades dessa linha visam criar condições para a participação popular no entendimento de seus papeis como agentes e cidadãos para a melhoria da qualidade de vida individual e coletiva e a educação é a forma mais eficiente de modificar e melhorar a qualidade de vida das pessoas (MRS, 2018). Essa linha de atuação comunga como pensamento de Paulo Freire (2000, p. 15) 
VI CIDESPORT/2019

Congresso Internacional

de Desempenho Portuário

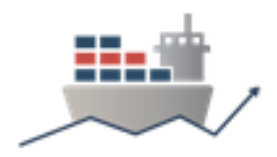

A educação ou funciona como instrumento usado para facilitar a integração da geração mais jovem na lógica do sistema atual e trazer conformidade à mesma, ou então torna-se a "prática da liberdade" - o meio através do qual homens e mulheres lidam crítica e criativamente com a realidade e descobrem como participar da transformação de seu mundo.

\section{CONTEXTO}

Entre as atividades criadas para atender o projeto, estão as aulas de reforço escolar para alunos do $6^{\circ}$ ao $9^{\circ}$ anos nas em três escolas municipais, sendo elas:

a) Escola de Educação Básica Profa Alba Herculano Araújo, situada no distrito da Taíba - São Gonçalo do Amarante - fruto de compensação ambiental, a escola foi construída pela Energia Pecém, usina termo elétrica situada no mesmo município, em parceria entre EDP Brasil e MPX Energia. Inaugurada em 2011 é a escola mais nova e mais bem estruturada, das integrantes do projeto de reforço escolar, com 20 salas de aula, biblioteca, cozinha com refeitório, quatro laboratórios, secretaria, sala de Coordenação Pedagógica e uma quadra poliesportiva. A escola funciona nos turnos matutino com escola regular e a noite, Educação de Jovens e Adultos (EJA).

b) Escola de Ensino Fundamental Gertrudes Prata Lima, no distrito do Pecém - São Gonçalo do Amarante. Fundada em 1968 com apenas uma sala para atender os alunos da professora Gonçalina Moreira Lima a escola passou por muitas reformas durante sua existência. Atualmente conta com seis saldas de aula, biblioteca, sala de informática e sala da coordenação pedagógica. A escola funciona nos turnos matutino com escola regular e a noite, EJA.

c) Escola de Educação Infantil e Ensino Fundamental Helena de Aguiar Dias, no distrito de Cumbuco - Caucaia. Fundada oficialmente em 1977 a escola possuía apenas duas salas de aula. Com o passar do tempo a escola foi reformada e ampliada e hoje possui 12 salas de aula, uma sala adaptada para biblioteca e quadra coberta. A escola funciona nos turnos matutino e vespertino com escola regular.

Para melhor qualificar a educação no Brasil foi criado o Seab (Sistema de Avaliação da Educação Básica) em 1990 e em 2005 foi realizada a primeira Avaliação Nacional do Rendimento Escolar, também conhecida como Prova Brasil que avalia, através de provas bienais, as disciplinas de português com foco em leitura, e matemática, com foco na resolução de problemas (MEC). Acompanhando o movimento de avaliação educacional o estado do Ceará criou, em 1992, o SPAECE (Sistema Permanente de Avaliação da Educação Básica do Ceará), que avalia, o quarto e o nono ano do ensino fundamental também para as disciplinas de português e matemática. Esse processo passa, desde sua implantação, por modificações como incorporação de novas metodologias de pesquisa e inovação tecnológicas (LIMA, 2007).

Segundo a pesquisadora Silva (2015) precisamos promover a educação ultrapassando a ideologia conteudista e instrumental e focar cada vez mais na educação com ênfase no desenvolvimento emocional, afetivo e nas habilidades sociais, ou seja, com práticas lúdicas sendo recurso prioritário para esse desenvolvimento integral do educando. Essa ideia é defendida pelo Rudolf Steiner, o idealizador da Pedagogia Waldorf.

Para essa pedagogia, na faixa etária de 7-14 anos, que compreende o ensino fundamental II, o desenvolvimento da criança tem objetivo de voltar-se para o funcionamento psicoemocional da criança, que possibilitem sua gradual evolução na 
utilização a serviço do pensamento e da aprendizagem, e que também possibilitem vivência emocional (SILVA, 2015).

Além da valorização da educação, o projeto ainda conta com o enaltecimento da comunidade pesqueira uma vez que as aulas são para os filhos (as), netos (as), sobrinhos (as) e parentes dos pescadores e marisqueiras da região.

É exatamente sobre a transformação social que a educação é capaz de suscitar que este projeto versa e tem como objetivo geral a melhoria no desempenho escolar dos alunos das escolas municipais E.E.F. Gertrudes Prata Lima, E.E.B Prof. ${ }^{a}$ Alba Herculano Araújo e E.E.I.E.F. Helena de Aguiar Dias, atendidos pelo reforço escolar do Porto do Pecém para que possam ingressar em escolas profissionalizantes do ensino médio.

Já os objetivos específicos desse projeto são: melhorar nas médias dos alunos atendidos nas três escolas pelo reforço escolar; incentivar os discentes das escolas assistidas a participar dos processos seletivos das escolas profissionalizantes; aumentar o número de alunos, nas escolas assistidas, que ingressam no ensino profissionalizante; formar monitores da própria comunidade como agentes de inspiração e transformação social; incentivando a formação profissional dos mesmos.

\section{INTERVENÇÃO}

Nas aulas do projeto do reforço escolar, que compreendem conteúdos de português, matemática e também educação ambiental, que é trabalhada enquanto eixo transversal e interdisciplinar, são tratados temas diversos, como raciocínio lógico, interpretação, cálculo básico, e, também, assuntos que compreendem a valorização da pesca, em que os alunos se reconhecem enquanto pertencentes às suas comunidades, criando uma ideia de pertencimento.

O processo de captação de monitores é realizado obedecendo alguns critérios, não de exclusão, mas de valorização de algumas características dos concorrentes. Por isso os critérios de valorização para selecionar os professores foram:

- $\quad$ Serem da própria comunidade. Assim há uma maior identificação entre os discentes e os monitores, criando laços afetivos e de empoderamento. Além de valorizar a população local e gerar renda para estes.

- Serem, na maioria, ex alunos das próprias escolas. Assim que o projeto foi implantado a ideia era de capacitar ex alunos, que se destacaram nas disciplinas de português e matemática, para ingressarem como monitores. Era uma forma de valorizar os melhores alunos, gerar renda e incentivar a continuação dos estudos.

Os monitores passaram por um treinamento que consistiu em realização palestras sobre a pedagogia Waldof. Foram apresentadas propostas da pedagogia e todo o treinamento foi realizado baseado na ludicidade, assim os monitores puderam vivenciar a metodologia de desenvolvimento psicoemocional.

As aulas do projeto são realizadas em três escolas sendo duas no município de São Gonçalo do Amarante e uma em Caucaia, conforme descrito no tópico anterior, e acontecem nos turnos matutino e vespertino, duas vezes por semana, servindo de atividade de contraturno para as crianças inscritas e são distribuídas conforme Quadro 1. 
VI CIDESPORT/2019

Congresso Internacional

de Desempenho Portuário

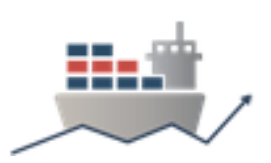

Quadro 1 - Distribuição das aulas de reforço escolar do Programa de Educação Ambiental do Terminal Portuário Porto do Pecém para o ano de 2019.

\begin{tabular}{|c|c|}
\hline Escola/Local & Turno \\
\hline \multirow{2}{*}{$\begin{array}{l}\text { E.E.F. Gertrudes Prata } \\
\text { Lima (Pecém) }\end{array}$} & Matutino \\
\hline & Vespertino \\
\hline \multirow{2}{*}{$\begin{array}{l}\text { E.E.B Prof.a Alba } \\
\text { Herculano Araújo (Taíba) }\end{array}$} & Matutino \\
\hline & Vespertino \\
\hline \multirow{2}{*}{$\begin{array}{l}\text { E.E.I.E.F. Helena de } \\
\text { Aguiar Dias (Cumbuco) }\end{array}$} & Matutino \\
\hline & Vespertino \\
\hline \multicolumn{2}{|c|}{$\begin{array}{l}{ }^{1} 6^{\circ} \text { e } 7^{\circ} \text { Ano }=\text { Português } / 8^{\circ} \text { e } 9^{\circ}=\text { Matemática } \\
26^{\circ} \text { e } 7^{\circ} \text { Ano }=\text { Matemática } / 8^{\circ} \text { e } 9^{\circ}=\text { Português } \\
{ }^{3} 6^{\circ} \text { e } 7^{\circ} \text { Ano }=\text { Português } / 8^{\circ} \text { e } 9^{\circ}=\text { Matemática } \\
{ }^{\circ} 6^{\circ} \text { e } 7^{\circ} \text { Ano }=\text { Matemática } / 8^{\circ} \text { e } 9^{\circ}=\text { Português } \\
{ }^{\circ} 7^{\circ} \text { Ano }=\text { Matemática } \\
6^{\circ} 7^{\circ} \text { Ano = Português } \\
7^{\circ} \text { e } 9^{\circ}=\text { Português } \\
8^{\circ} 8^{\circ} \text { e } 9^{\circ}=\text { Matemática } \\
1^{10} 7^{\circ} \text { Ano = Português } / 8^{\circ} \text { e } 9^{\circ}=\text { Matemática } \\
117^{\circ} \text { Ano = Matemática } / 8^{\circ} \text { e } 9^{\circ}=\text { Português }\end{array}$} \\
\hline
\end{tabular}

Para melhor análise das médias escolares do ano de 2019 dos alunos das escolas assistidas pelo projeto de reforço escolar foram criados três grupos, sendo eles:

a) Média geral, que estão compreendidos todos os alunos do ano em questão;

b) Com reforço, que compreende o grupo de alunos que participam do reforço em um determinado ano;

c) Sem reforço, que compreende os alunos de um determinado ano que não são atendidos pelo reforço escolar.

Todos estes grupos compreendem as matérias de Matemática e Português.

\section{RESULTADOS OBTIDOS}

Desde sua implantação, em 2017, o reforço alcançou bons resultados. Já nos primeiros seis meses de sua implantação, os alunos do reforço conseguiram uma taxa de aprovação de $50 \%$, sendo 09 alunos da Escola Alba Herculano e 08 alunos da Escola Helena.

Outro dado importante é que, ainda em 2017, um aluno da escola Helena de Aguiar Dias conseguiu o $1^{\circ}$ lugar no Instituto Federal do Ceará. Tal feito foi importante não apenas para o discente, mas também serviu como motivação para os demais estudantes da escola que viram nele a possibilidade real de conseguir modificação social por meio da educação no ensino público.

O índice de aprovação geral somando-se todas as escolas foi de $80 \%$ em 2018. A escola Alba Herculano foi a que obteve melhor despenho com 13 alunos inscritos nas aulas de reforço, todo sesses alunos se inscreveram para a seleção das escolas profissionalizantes e 12 foram aprovados, sendo o índice de aprovação de 92,3\%. Esta escola teve um aumento geral de inscritos e de aprovados classificando o total de 23 alunos. 
$\mathrm{Na}$ Escola Gertrudes da Prata tivemos 30 alunos inscritos na aula de reforço escolar, sendo que cinco se inscreveram e foram aprovados pelas escolas profissionalizantes, tendo como resultado 100\% de aprovação nos inscritos em 2018.

Por fim, na Escola Helena Prata tivemos 30 alunos inscritos na aula de reforço escolar e 12 alunos foram aprovados nas escolas profissionalizantes, um aumento de $50 \%$ em relação ao ano de 2017.

Esses dados nos mostram que o reforço escolar ofertado pela CIPP S.A tem obtido excelentes resultados. Houve aumento na porcentagem de aprovados, como mostra o Gráfico 1.

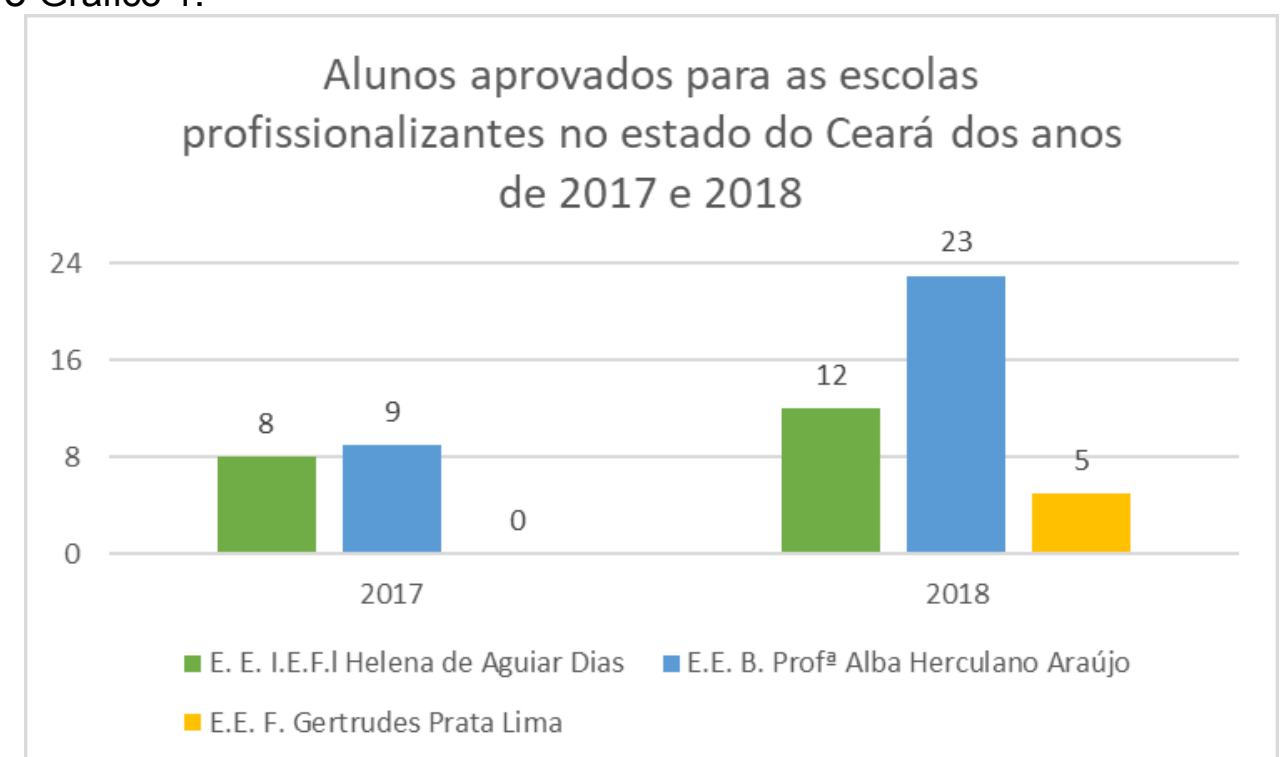

Gráfico 1 - Quantidade de alunos das escolas assistidas pelo projeto de reforço escolar aprovados em escolas profissionalizantes nos anos de 2017 e 2018.

Vale ressaltar que a escola Gertrudes não participou do primeiro ano de atuação do reforço escolar, o que não nos permitiu uma comparação entre os dois anos de atividade do projeto.

Em 2019 foi iniciada a avaliação do desempenho escolar por meio do acompanhamento das médias dos alunos que participam do reforço e dos que não participam nas três escolas atendidas: 

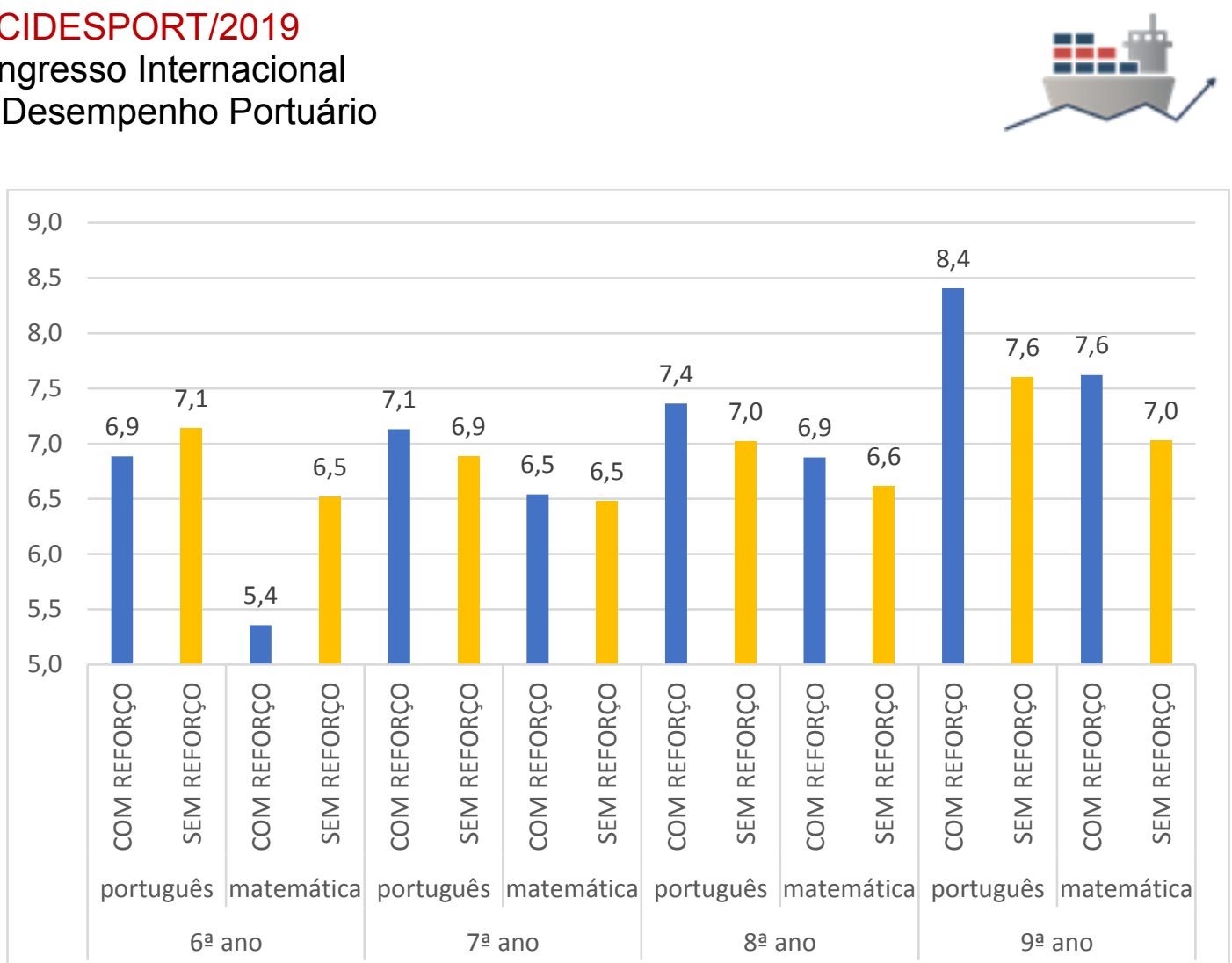

Gráfico 2 - Comparativo das médias dos alunos com e sem reforço nas escolas assistidas pelo PEA em 2019.

O $6^{\circ}$ ano é atendido apenas pela escola E.E.I.E.F. Helena de Aguiar Dias e a turma é composta por alunos repetentes ou com dificuldade em aprendizado, necessitando de uma maior atenção e um acompanhamento escolar mais minucioso para que possam ter um melhor entendimento do conteúdo.

Já nos demais anos a média geral, das três escolas, dos alunos que fazem parte do reforço é maior do que a dos alunos que não são assistidos pelo programa, com médias de até 0,8 ponto maior.

O corpo de docentes que atua no projeto hoje contempla seis pessoas, sendo três responsáveis pelo ensino de português e três de matemática.

Todos os monitores residem na comunidade e quatro são ex alunos das escolas. $\mathrm{O}$ fato de terem estudados no mesmo lugar que lecionam faz com que eles tenham melhor conhecimento sobre a realidade do local e consigam melhor adaptar as aulas para os alunos assistidos.

Dos seis professores, dois já possuem graduação, uma em pedagogia e uma em matemática licenciatura, e quatro estão cursando o ensino superior, dois em pedagogia, uma em matemática e um em enfermagem. Entre os professores do projeto apenas uma ainda não tem formação superior e nem está cursando. Se trata da professora mais nova do grupo que já se inscreveu no curso de pedagogia e está no aguardo a formação de turma para que as aulas sejam iniciadas.

No ano de 2019 uma aluna do reforço escolar foi premiada no Concurso Cultural de Redação sobre Meio Ambiente "Eu cuido do Mundo". O concurso foi realizado pela Secretaria Municipal de Educação de São Gonçalo do Amarante em comemoração ao dia mundial do meio ambiente e a aluna do reforço da E.E.B. Profa Alba Herculano Araújo conquistou o primeiro lugar, como mostra imagem abaixo: 
VI CIDESPORT/2019

Congresso Internacional

de Desempenho Portuário
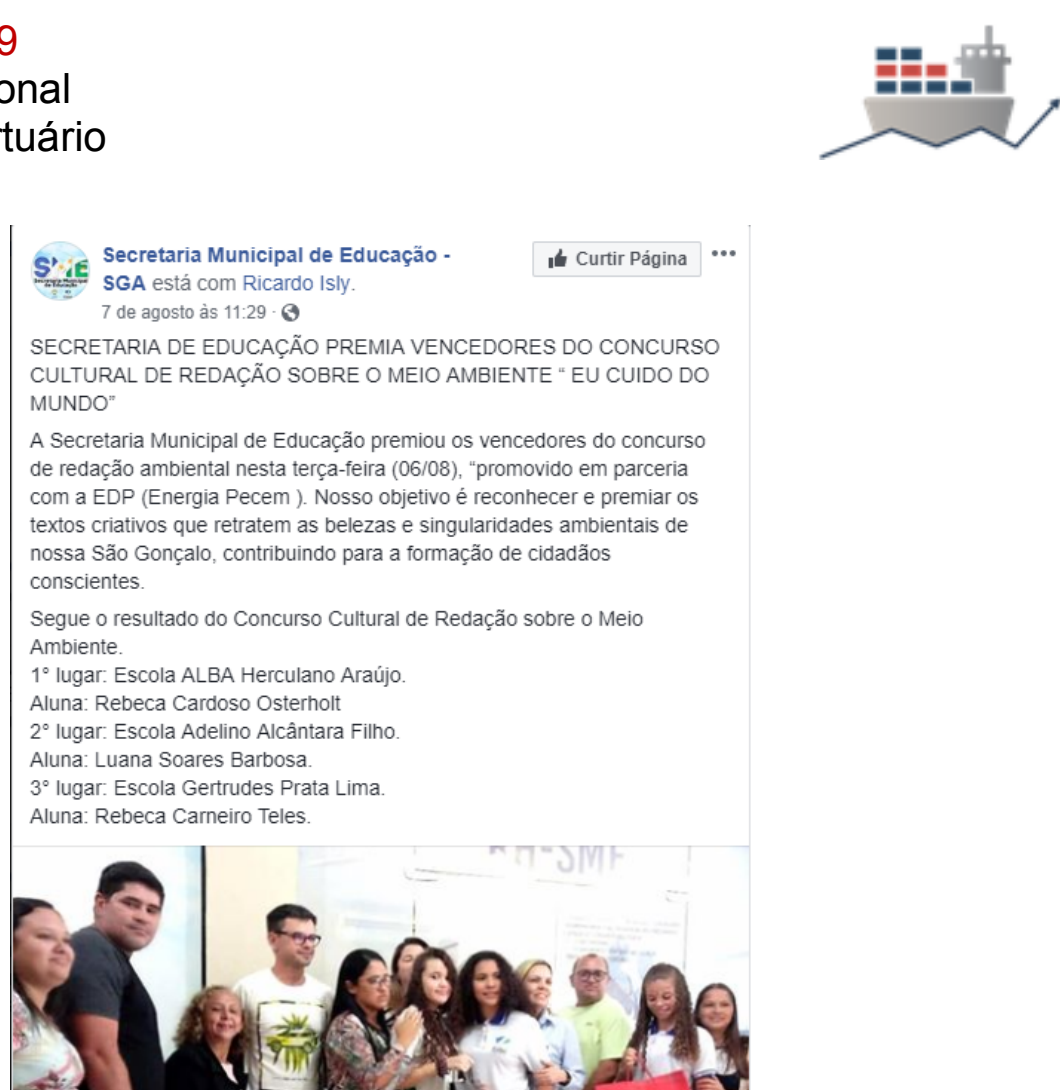

Figura 1 - Premiação do Concurso Cultural de Redação sobre o Meio Ambiente "Eu Cuido do Mundo" realizado pela Secretaria Municipal de Educação de São Gonçalo do Amarante (foto retirada das redes sociais da secretaria).

\section{CONCLUSÃO}

Os resultados alcançados pelas atividades do reforço escolar atenderam os objetivos do Projeto e podem ver evidenciados pela melhoria do desempenho escolar dos alunos participantes, pelo aumento do número de inscritos para participar do processo seletivo das escolas profissionalizantes, assim como pelo aumento no número de aprovados nestas escolas.

Os professores do reforço obedeceram os critérios estabelecidos na seleção e isso traz benefícios para o fortalecimento da comunidade local como: valorização e empoderamento da comunidade, já que os monitores são também exemplo de como a educação pode transformar a vida, trazendo geração de renda e possibilitando o investimento nos estudos, como acontece com a maioria dos monitores do projeto.

Como resultados adicionais tivemos dois alunos destaques, um que ficou em primeiro lugar sendo um no concurso do IFCE e outro em um concurso municipal de redação sobre meio ambiente, tema este que é trabalhado de forma transversal durante as aulas de reforço.

Dessa forma, é possível afirmar que o Projeto de Reforço Escolar é uma iniciativa transformadora desenvolvida na área de influência do Porto do Pecém e que visa melhorar a qualidade de vida dessas comunidades por meio da educação.

\section{REFERENCIAS}

BRASIL, Ministério da Educação. Prova Brasil. Disponível em < http://portal.mec.gov.br/prova-brasil>. Acessado em 25/08/2019.

CEARÁ. Secretaria Estadual de Desenvolvimento Econômico. Missão e Valores do Complexo Industrial e Portuário do Pecém. Disponível em < http://www.cearaportos.ce.gov.br/index.php/institucional/missao-e-objetivosl>. Acessado em 25/08/2019. 
VI CIDESPORT/2019

Congresso Internacional

de Desempenho Portuário

CEARÁ. Secretaria Estadual de Educação. Escolas Estaduais de Educação Profissional no Ceará. Fortaleza, CE, 2018.

DE SOUSA, A. P. A importância da parceria entre família e escola no desenvolvimento educacional. Revista Iberoamericana de Educación, v. 44, n. 7, p. 1-8, 2008.

FREIRE, P. Pedagogia da autonomia: saberes necessários à prática educativa.22 ed. São Paulo: Paz e Terra, 2002

IBGE, Censo Demográfico. Censo demográfico 2010: Características da população e dos domicílios: resultados do universo. Acesso em 25/08/2019, v. 20, 2012.

IBGE, IBDGEE; IBGE. Pesquisa Industrial Anual-PIA. 2017.

LIMA, A. C.. O sistema permanente de avaliação da educação básica do ceará (SPAECE) como expressão da política pública de avaliação educacional do estado. Universidade Estadual do Ceará. Fortaleza: UECE, 2007.

MATIAS, N. C. Fe. A importância de políticas públicas além da escola formal para o desenvolvimento infantil e adolescente: Uma revisão de literatura. Interação em Psicologia, v. 14, n. 1, 2010.

MRS. Plano Básico Ambiental (PBA) Integrado do Terminal Portuário do Pecém. Brasília, DF, v4, p.215, 2018.

SILVA, D. A. de A. Educação e ludicidade: um diálogo com a Pedagogia Waldorf. Educar em Revista, n. 56, p. 101-113, 2015. 